\title{
Fetal Frontal Cortex Transplanted to Injured Motor/Sensory Cortex of Adult Rats. II. VIP-, Somatostatin"', and NPY-Immunoreactive Neurons
}

\author{
Frank R. Sharp, Manuel F. Gonzalez, and Stephen M. Sagar \\ Departments of Neurology and Physiology, University of California, and the Veterans Administration Medical Center, San \\ Francisco, California 94121
}

\begin{abstract}
Fetal frontal cortex transplants that survived 2-9 months in cavities in adult rat motor/sensory cortex were processed for vasoactive intestinal polypeptide (VIP), somatostatin 14 (SS), and neuropeptide $Y$ (NPY) immunocytochemistry, and NADPH-diaphorase (NADPH-d) histochemistry. All transplants had surviving VIP, SS, NPY, and NADPH-d neuronal perikarya and fibers with normal adult morphology. The number of peptidergic neurons within transplants, however, often appeared to be less than that in equivalent areas of host cortex. Most transplanted SS and VIP neuronal perikarya did not migrate to form the laminae characteristic of normal cortex. A few transplants had SS and VIP cells arranged in laminae in which the VIP processes were parallel to one another and perpendicular to one transplant surface, approximating normal host neocortex.

VIP, NPY, and SS fibers crossed between host brains and transplants, suggesting that peptide host-transplant interactions are possible. All adult hosi cortical and most transplanted NPY neurons colocalized with NADPH-d. The failure of some transplanted NPY neurons to express NADPH-d suggests these transplanted cells may be functionally impaired, but that they can survive without the NADPH-d enzyme.
\end{abstract}

Transplants partially reverse the genetic peptide hormone deficits in Brattleboro and hypogonadotrophic rats (Gash et al., 1980; Krieger et al., 1982). Peptide containing neurons also survive in fetal cortical transplants (Ebner et al., 1984; Floeter and Jones, 1985; Connor and Bernstein, 1986). Though the functions of cortical peptides are unknown, normal numbers of properly distributed peptidergic neurons are probably important for normal cortical function.

Of the cortical peptides, both vasoactive intestinal polypeptide (VIP) and somatostatin (SS) stimulate glycogenolysis in vitro (van Calker et al., 1980; Magistretti et al., 1981). Neuropeptide Y (NPY) and VIP affect cerebral blood flow when injected intracerebrally (McCulloch and Edvinsson, 1980; Edvinsson et al., 1984). Therefore, the abnormally low glucose metabolic rates previously detected in fetal cortical transplants (Sharp and Gonzalez, 1984) might be related to transplanted peptidergic neurons.

\footnotetext{
Received July 21, 1986; revised Mar. 9, 1987; accepted Apr. 14, 1987

We wish to thank Ms. Janct Loken, Ms. Ann Poncelet, and Mr. Matthew Morton for technical assistance, and Ms. Janet Loken for preparing the figures. We gratefully acknowledge the support of this work by United Cerebral Palsy Foundation Grant R-354-85, by National Science Foundation Grant BNS-8503176, and by Merit Review support from the Research Service of the Veterans Administration. Correspondence should be addressed to Dr. Frank R. Sharp, Veterans Administration Medical Center, Department of Neurology V127, 4150 Clement Street, San Francisco, CA 94121.

Copyright (C) 1987 Society for Neuroscience $0270-6474 / 87 / 103002-14 \$ 02.00 / 0$
}

Abnormalities of transplanted cortical peptidergic neurons have been reported by Ebner et al. (1984). Though their cortical transplants had VIP-, SS-, and cholecystokinin (CCK)-like immunoreactive fibers, many had no immunoreactive perikarya. Since few fibers crossed between transplant and host cortex, they reasoned that transplanted peptidergic perikarya were not visualized with their methods. Alternatively, host peptide fibers that had sprouted into the transplant might not have been visualized. Because of the importance of either result, and because the NADPH-d neurons described in the previous paper (Gonzalez and Sharp, 1987) colocalize with NPY and SS, peptidergic neuronal survival in cortical transplants was re-examined. VIP-, SS-, and NPY-like immunoreactive neuronal perikarya and fibers were observed in every transplant, along with some fibers crossing between adult host neocortex and cortical transplants.

\section{Materials and Methods}

Methods used to transplant fetal frontal cortex from 18-d-old rat embryos to cavities created in the motor/sensory cortex of adult host SpragueDawley rats are described in the preceding paper (Gonzalez and Sharp, 1987). After 2-9 month survivals, hosts were anesthetized with ketamine $(80 \mathrm{mg} / \mathrm{kg})$ and xylazine $(8 \mathrm{mg} / \mathrm{kg})$, and perfused through the ascending aorta with $50 \mathrm{ml}$ of $0.1 \mathrm{M}, \mathrm{pH} 7.4$, PBS $(0.9 \%)$, followed by $300-500 \mathrm{ml}$ of freshly prepared $4 \%$ paraformaldehyde in PBS. In the 9 subjects whose brains were sectioned on a Hacker cryostat, the fixative was followed by $200 \mathrm{ml}$ of $10 \%$ sucrose in PBS. After being stored overnight in the same solution at $4^{\circ} \mathrm{C}$, brains were frozen in 2-methylbutane cooled to $-30^{\circ} \mathrm{C}$ and embedded in Lipshaw matrix. Fortymicrometer-thick coronal sections cut at $-20^{\circ} \mathrm{C}$ in the cryostat were picked up onto gelatin-coated slides and dried at room temperature. The brains of 7 additional subjects were removed immediately following the $4 \%$ paraformaldehyde perfusion; their transplants were covered with $4 \%$ agarose (Sigma, Type VII); and 50 - $\mu \mathrm{m}$-thick coronal sections were cut on a Vibratome. Serial coronal sections through lesion sites and transplants were saved from Vibratome- and cryostat-sectioned brains. The avidin-biotin-peroxidase technique (ABC Vectastain; Vector Laboratories, Burlingame, $\mathrm{CA}$ ) was used to process tissue for immunocytochemistry (Hsu et al., 1981; Sagar et al., 1985).

Sections clit in the cryostat and dried onto slides were placed in $5 \%$ goat serum, $5 \%$ nonfat dried milk in PBS for $3 \mathrm{hr}$, then in $1 \%$ hydrogen peroxide in PBS for $20 \mathrm{~min}$, followed by three $5 \mathrm{~min}$ rinses in PBS, all at room temperature. Nonfat dried milk was used to reduce nonspecific binding due to endogenous avidin (Duhamel and Johnson, 1985). Sections on slides were then incubated in primary antiserum diluted 1:1500 in $0.5 \%$ Triton X-100 in PBS in a warm room $\left(38^{\circ} \mathrm{C}\right)$ for $72 \mathrm{hr}$. After a $5 \mathrm{~min}$ rinse in PBS at $22^{\circ} \mathrm{C}$, sections were placed in $5 \mathrm{mg}$ biotin $/ 100$ $\mathrm{ml}$ PBS for $1 \mathrm{hr}$ to absorb biotin-binding sites. A second antibody was then added (one drop of biotinylated goat anti-rabbit $\mathrm{IgG}$ from the $\mathrm{ABC}$ kit per $10 \mathrm{ml}$ of $0.5 \%$ Triton X-100 in PBS) and the sections incubated for $24 \mathrm{hr}$ at $38^{\circ} \mathrm{C}$ without agitation. After two $5 \mathrm{~min}$ PBS washes, the tissue was incubated in the avidin-biotinylated HRP complex from the $\mathrm{ABC}$ kit for $3 \mathrm{hr}$ at room temperature. Following three $5 \mathrm{~min}$ PBS rinses, the sections on slides were reacted for HRP using filtered diaminobenzidine (DAB) $(0.5 \%$ in PBS) and $0.03 \%$ hydrogen peroxide. Finally, the sections were rinsed several times in PBS, dehydrated, and coverslipped. 

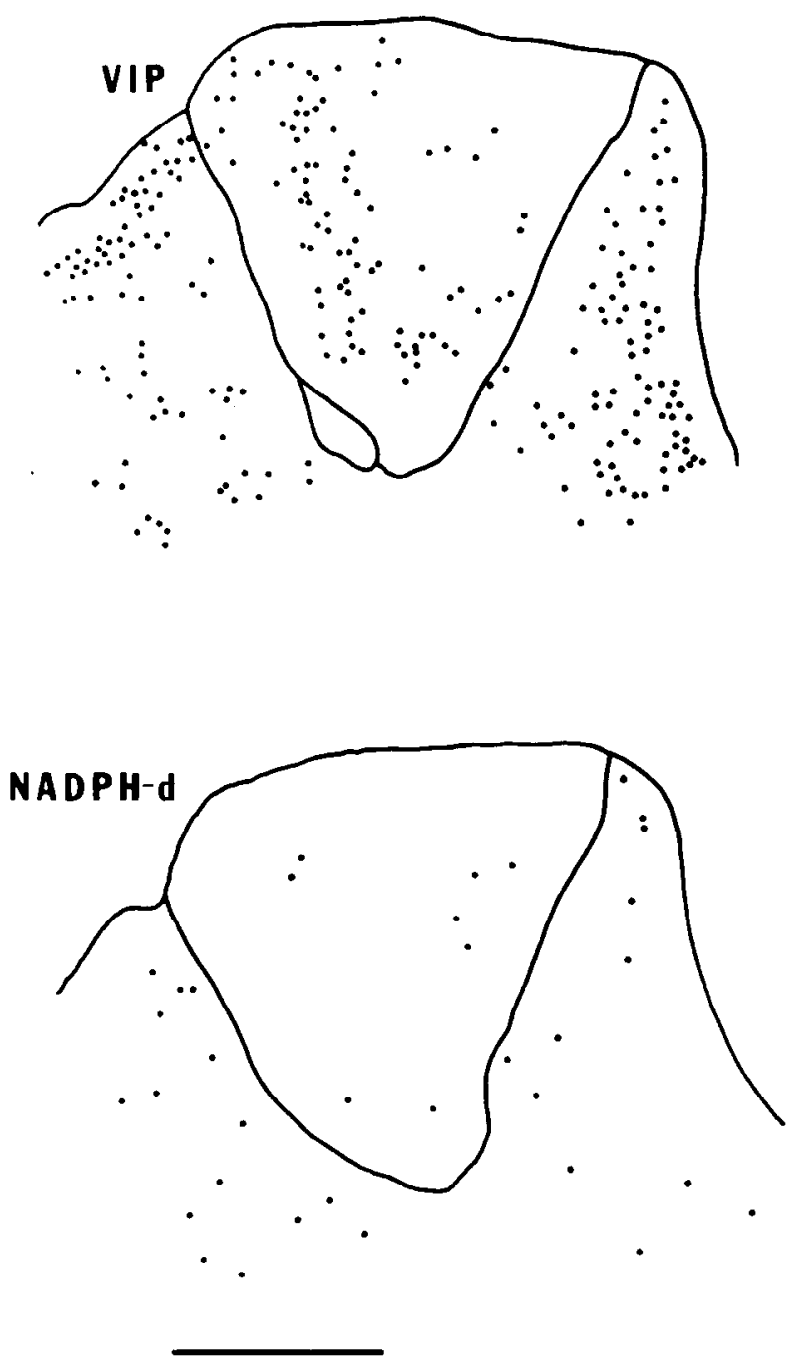
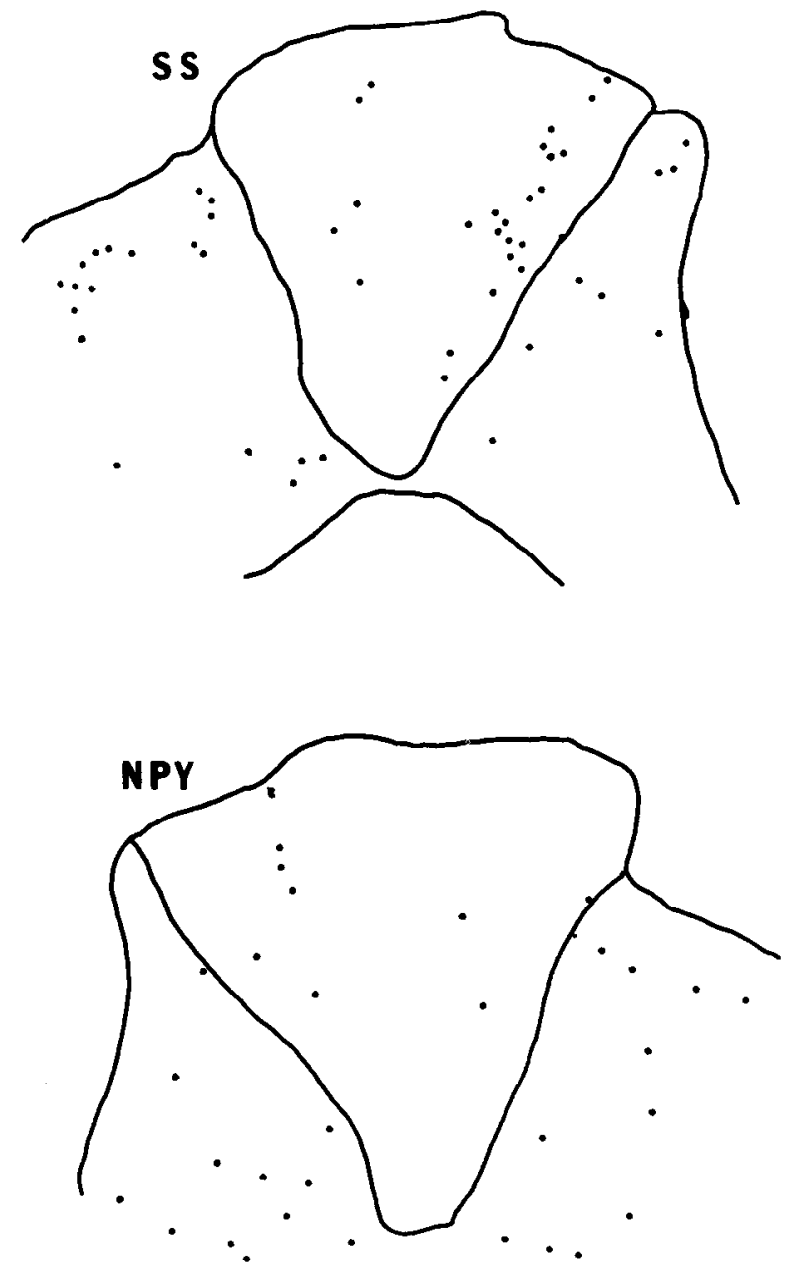

Figure 1. Plots of immunoreactive neuronal perikarya on camera lucida drawings of the cortical transplant and adjacent host cortex of subject 73. Immunocytochemistry was performed 9 months after transplantation. VIP, Vasoactive intestinal polypeptide; $S S$, somatostatin-14; $N P Y$, neuropeptide Y; $N A D P H$ - $d$, NADPH-d enzyme. Calibration bar, $1 \mathrm{~mm}$.

Vibratome-sectioned brains were treated identically, with the following exceptions. Following cutting, sections were placed in PBS and processed in wells throughout. The Triton X-100 concentration was reduced to $0.2 \%$. The concentration of primary antibody was increased to $1: 1000$. Sections were incubated in wells on a shaker at $4^{\circ} \mathrm{C}$ for a period of 72 $\mathrm{hr}$ for the primary antibody and for a period of $24 \mathrm{hr}$ for the second antibody. Following the HRP reaction, which concluded the immunocytochemistry, vibratomed sections were floated onto gelatinized slides while in PBS, dried, dehydrated, and coverslipped.

Selected sections from all Vibratome- and cryostat-sectioned brains were Nissl-stained with neutral red cresyl violet. Margins between host brains and transplants were drawn on the Nissl-stained sections, and adjacent immunocytochemically stained sections were determined on the basis of several criteria. These included the presence of gaps between host and transplant, gliotic areas between host and transplant, differences of stain intensity, and clear lamination of host cortical neurons, as compared to the usual lack of lamination of transplanted cortical neurons.

Nine animals not reported on above or in the preceding study (Gonzalez and Sharp, 1987) were also perfused, their brains removed and sectioned on the Vibratome and reacted for NADPH-diaphorase (NADPH-d) using the method of Sherer-Singler et al. (1983). Following NADPH-d staining, these sections were processed for either VIP, SS, or NPY immunocytochemistry, as described above. NADPH-d-positive cells were light to dark blue. Peptide-containing, immunocyto- chemically stained, HRP-reacted cells were light brown in color. Double-labeled cells containing both NADPH-d and a peptide were dark blue-brown to black in color and could therefore be distinguished from cells single-labeled for NADPH-d and peptides that were blue or brown, respectively.

The primary antisera to VIP, SS-14, and NPY were purchased from Cambridge Research Biochemicals (Cambridge, UK). The specificities of the primary antisera were demonstrated by abolition of fiber and cell body staining when the primary antiserum was omitted, or when synthetic VIP or NPY $(1 \mathrm{nmol} / \mathrm{ml})$ or synthetic SS-14 $(1 \mathrm{ng} / \mathrm{ml})$ was included in the incubation medium of the corresponding primary antibody. Inclusion of VIP, NPY, motilin, CCK, and neurotensin at concentrations of $10 \mathrm{nmol} / \mathrm{ml}$ had no effect on immunostaining for SS14 , whereas some decrease in staining was observed with SS-28. Inclusion of SS, NPY, motilin, CCK, and neurotensin $(10 \mathrm{nmol} / \mathrm{ml})$ had $\mathrm{no}$ effect on VIP staining. While the inclusion of SS, VIP, motilin, CCK, and neurotensin $(10 \mathrm{nmol} / \mathrm{ml})$ had no effect on NPY immunostaining, some decrease in immunoreactivity for this peptide was observed following the inclusion of peptide YY (PYY) and avian pancreatic polypeptide (APP) $(10 \mathrm{nmol} / \mathrm{ml})$.

Camera lucida drawings of at least 4 sections through the transplant and adjacent host cortex were made for each subject. The VIP-, SS-, NPY-, and NADPH-d-labeled cells were plotted on these drawings using bright-field, dark-field, phase, and Nomarsky optics. Only unequivocally labeled cells that had at least one process extending from the 


\section{VIP}
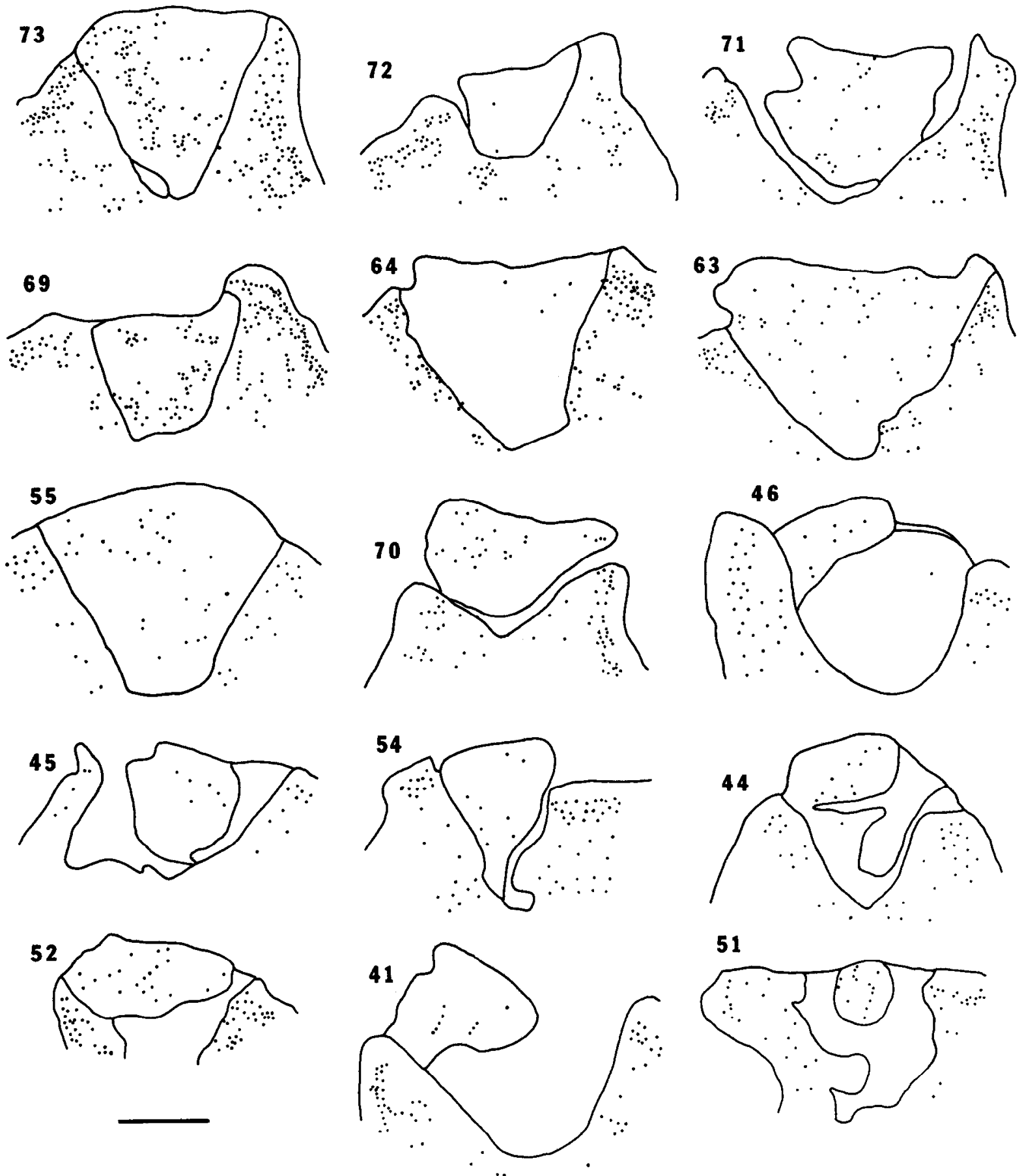

Figure 2. VIP-like immunoreactive neuronal perikarya for subjects $41-73$, plotted on camera lucida drawings of transplant and adjacent host cortex. Calibration bar, $1 \mathrm{~mm}$.

perikarya were plotted. The drawings with the largest number of immunoreactive perikarya within each transplant are pictured in Figures $1,2,6$, and 8

\section{Results}

VIP-, SS-14-, and NPY-like immunoreactive neuronal perikarya and fibers were found in every transplant (Figs. 1-10). If a transplant had ncarly normal numbers of onc type of peptidccontaining neuron, it generally had nearly normal numbers of the others (Fig. 1). Similarly, if one type of neuron was reduced in number, the other types were also diminished (Figs. 2, 6, 8). VIP-containing neurons were the most numerous of the cells examined, SS-14 neurons the next most numerous, and NPY and NADPH-d neurons the fewest and most scattered (Figs. 1, $2,6,8)$.

VIP neuronal perikarya, though found in all layers, were most numcrous in laycrs 2 and 3 of host cortex (Figs. $1 ; 2 ; 3, A-C$ ). Most transplants appeared to have fewer VIP neuronal perikarya 

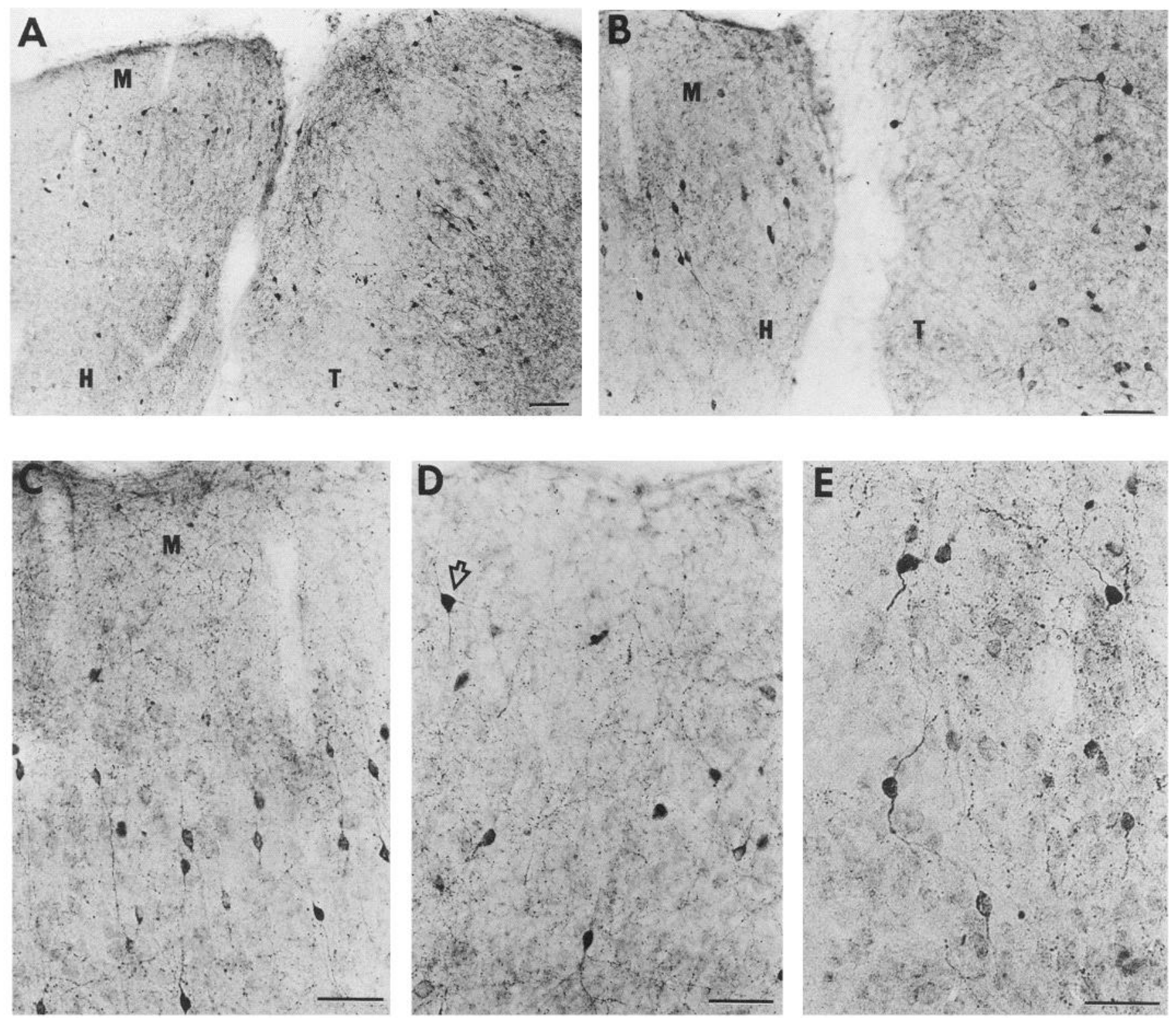

Figure 3. Photomicrographs of VIP neurons in transplant 73 showing host $(H)$ cortex $(A-C)$ and adjacent transplant $(T)$ cortex $(A, B, D, E)$. Open arrow, $D$, shows uncommon multipolar VIP neuron in transplant. $M$, molecular layer 1 of host cortex. Calibration bars, $50 \mu \mathrm{m}$.

per unit area than did equivalent areas of adjacent host cortex (Figs. 2, nos. 72, 71, 64, 63, 46, 45, 54, 44, and 41; 3, C-E). Some transplants (Figs. $1 ; 2$, nos. 73 and $69 ; 3, A, B, D$ ) had nearly normal numbers of VIP perikarya compared to host cortex (Figs. 1; 2, nos. 73 and $69 ; 3, A-C$ ), and the distribution of these cells sometimes suggested the cellular concentration in laminae II and III found in host cortex (Fig. 2, nos. 73 and 69). Most VIP cells in host cortex were bipolar neurons whose processes were parallel to each other and perpendicular to the pial surface (Figs. 3, $A-C ; 4, A, B$ ). A few transplants also had VIP neuronal processes parallel to each other and perpendicular to one surface of the transplant, though the processes were oriented at angles to the processes of the host VIP cells (Fig. 3, $A, B$ ). In most transplants, however, the bipolar VIP neurons appeared to be randomly aligned (Fig. $3 E$ ). The morphology and size of most bipolar VIP neurons within transplants (Figs. 3, $A, B, D$, $E ; 4 D$ ) appeared quite similar to those of host VIP neurons
(Figs. 3, $A-C ; 4, A, C$ ). A few transplanted VIP neurons did appear to be abnormal (Fig. 4, E, F). A few multipolar VIP neurons were also present in normal host cortex (Fig. $4 C$ ) and transplants (Fig. $3 D$, open arrow).

VIP-stained fibers frequently crossed the interface between host $(\mathrm{H})$ and transplanted $(\mathrm{T})$ cortex (Fig. $5 B$ ). These fibers were best seen in sections stained in wells. In most cases it was not possible to state where the fibers originated. On occasion, however, fibers were traced from a cell in the transplant (Fig. $5 \mathrm{~A}$, open arrow) across the transplant-host interface and into the host brain (Fig. $5 A$, solid arrows).

Every transplant contained SS-14-like immunoreactive perikarya and fibers (Figs. 6, 7). Some transplants appeared to have very few surviving perikarya (nos. 71 and 70 ) per unit area, while others had nearly normal numbers (nos. 73 and 69) compared to equivalent areas in adjacent host cortex (Fig. 6). Though SS neurons were found throughout normal host cortex, they 

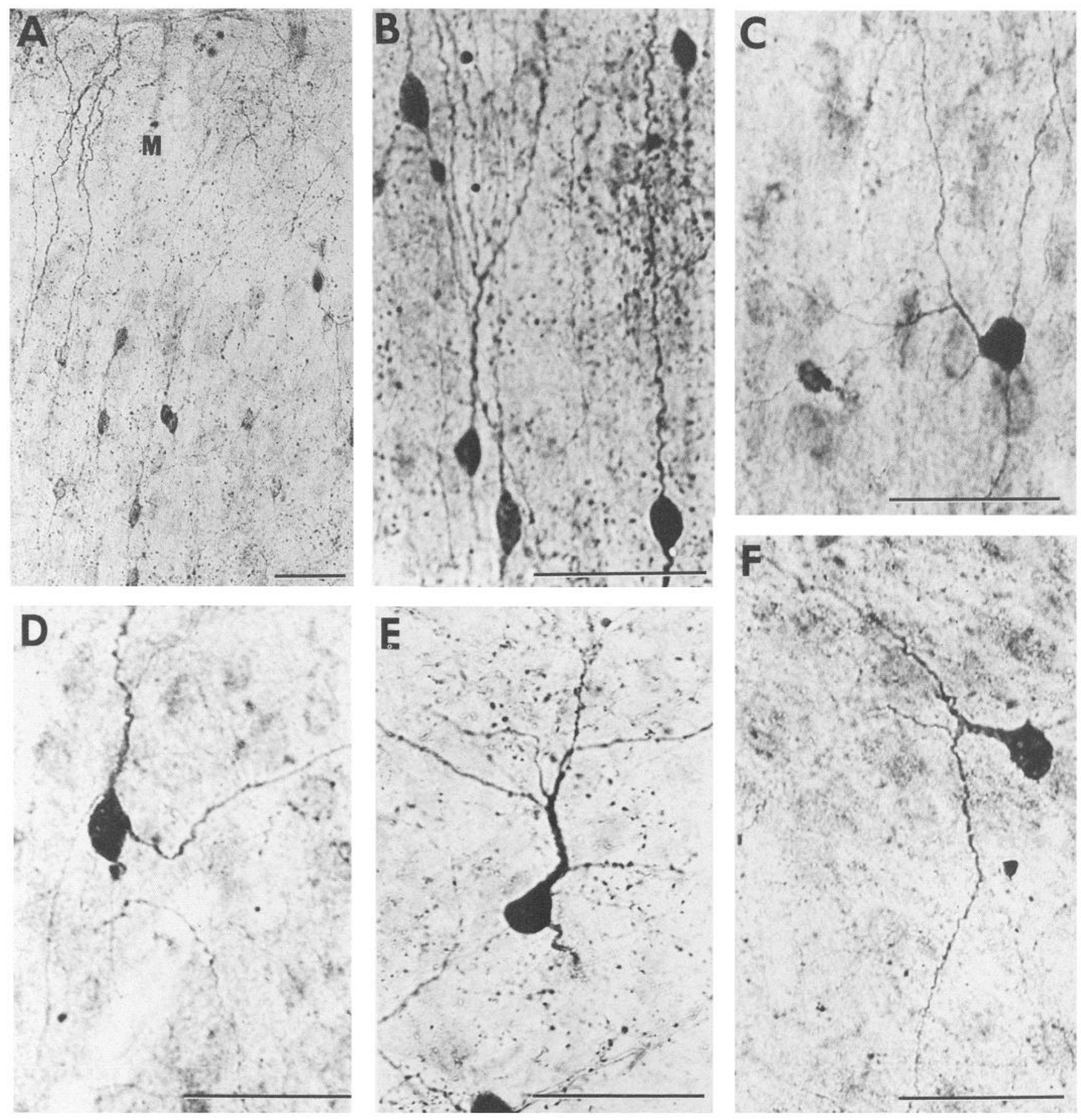

Figure 4. VIP-like immunoreactive neurons in normal host brains showing bipolar $(A, B)$ and multipolar $(C)$ morphology. Most transplant VIP neurons also had bipolar morphology $(D)$, but a few had somewhat abnormal morphologies $(E, F)$. Calibration bars, $40 \mu \mathrm{m}$.

were concentrated in layers 2 and 3 (Fig. 6). Only a few transplants had SS neurons arranged in arrays (Fig. 6, nos. 73, 69, and 63) vaguely resembling laminae II and III in the host cortex. In one, however, SS and VIP neurons congregated in different transplant regions (no. 73), whereas both cell types were concentrated in layers 2 and 3 of normal host cortex (Figs. 1, 2, 6). The morphology of SS neurons was similar in transplants (Fig. 7, $A, B, E$ ) and host cortex (Fig. 7, $A-D, F$ ). Although Figure $7 F$ shows the process of a host $(\mathrm{H}) \mathrm{SS}$ neuron extending into a transplant $(\mathrm{T})$, few SS fibers were visualized crossing host-transplant interfaces. This could be related to the relatively few fibers stained in both host and transplant with this particular antibody. Within host cortex and transplants stained for both SS and NADPH-d, there were many SS-positive, NADPH-d-negative neurons (Fig. $7 G$, lower arrow), and occasional SS-positive, NADPH-d-positive neurons (Fig. 7G, upper arrow).

Neuropeptide Y-immunoreactive neurons were distributed throughout all layers of host neocortex except lamina I (Fig. 8). 

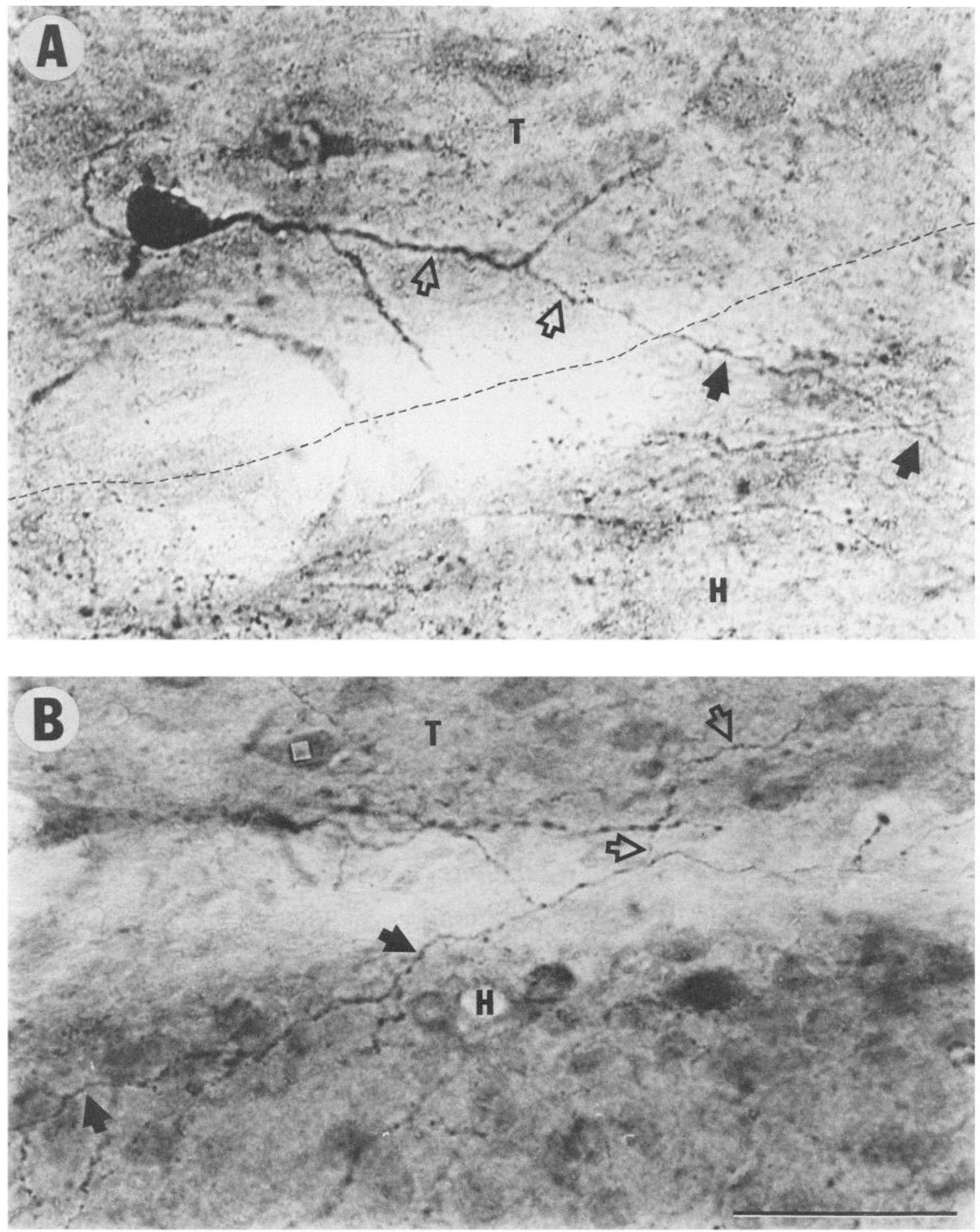

Figure 5. A, VIP-like immunoreactive neuron in a transplant $(T)$ sends a fiber from transplant (open arrows) to host $(H)$ brain (solid arrows). B, Multiple VIP fibers cross interface between transplant $(T)$ and host $(H)$. Calibration bar, $40 \mu \mathrm{m}$.

Transplant NPY neurons were generally distributed throughout the transplant, except in a few instances where neurons survived at the edges (Fig. 8, no. 41) or in clumps within the transplant (Fig. 8, no. 44). The number of NPY neurons in some transplants approximated the number in equivalent areas of adjacent cortex (Fig. 8, nos. 73, 72, 69, 45, and 51). In other transplants their number was reduced (Fig. 8, nos. 71, 55, 46, 70, 44, 52, 54, and $41)$. The morphology of NPY neurons within surviving trans- plants (Fig. 9, $B, D, F$ ) was similar in most instances to the morphology of the multipolar NPY neurons in host neocortex (Fig. 9, $A, C, E$ ). However, Figure $10 F$ shows a transplant NPY neuron with abnormal processes, one of which traversed the transplant-host interface for a short distance.

Sections double-stained for NPY and NADPH-d revealed that all host cortex cells containing NPY also contained NADPH-d (Fig. 10, $C-E$ ) In every transplant except one, NPY 

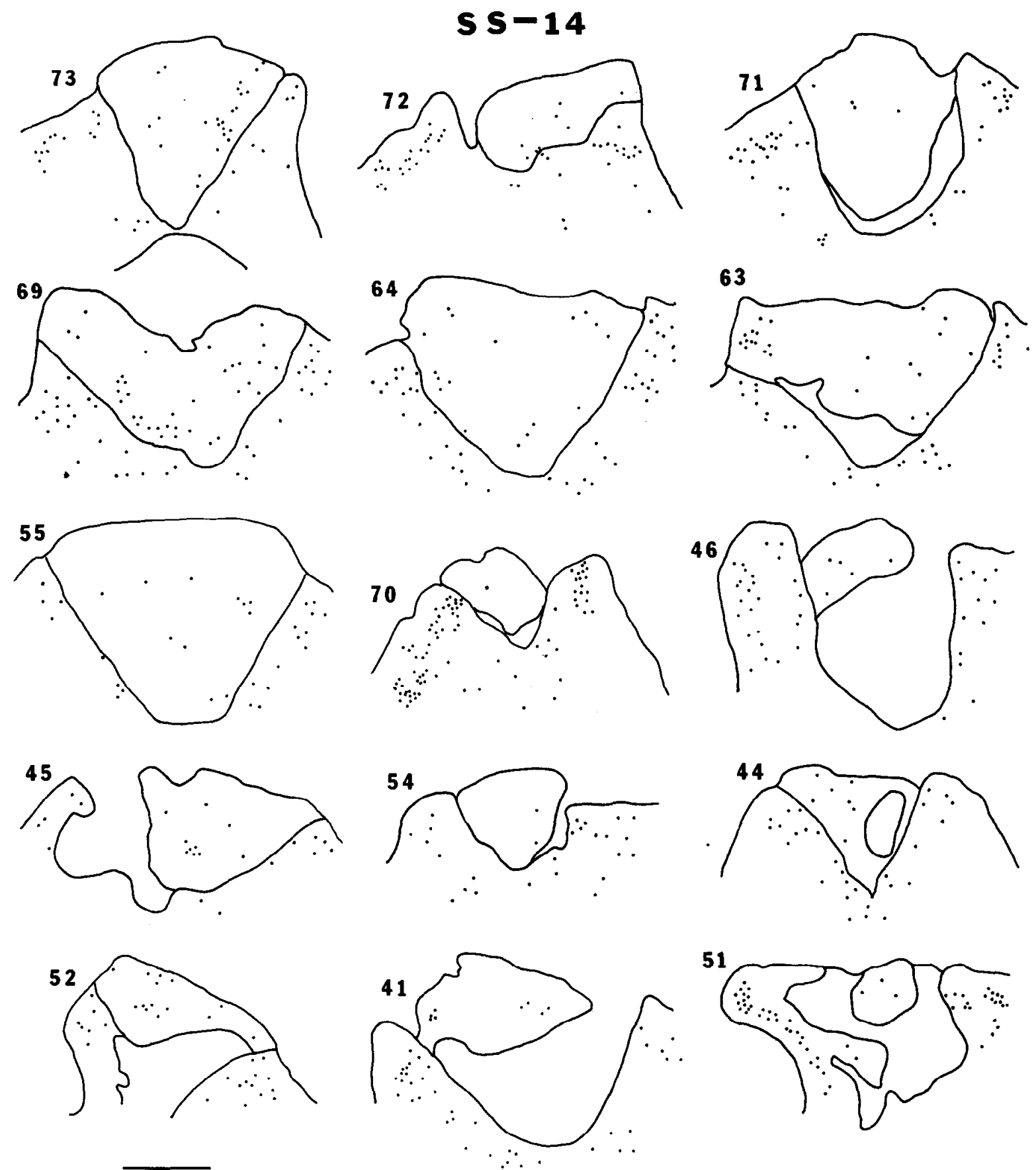

Figure 6. SS-14-like immunoreactive neuronal perikarya for subjects 41-73, plotted on camera lucida drawings of transplant and host cortex. Calibration bar, $1 \mathrm{~mm}$.

and NADPH-d also colocalized in the same neurons (Fig. 10, $B, C, E$ ). One transplant had a segment (upper right of transplant in Fig. $10 B$ ) in which all neurons in that region stained for NPY but did not stain for NADPH-d (Fig. 10, B-D). A solid arrow within this region (Fig. 10B) points to one of these NPY-positive, NADPH-d-negative neurons (also seen at higher power in Fig. $10, C, D$ ). The open arrow in the transplant in Figure $10 B$ points to one of the many transplanted neurons double-labeled for NPY and NADPH-d (also shown with open arrows in Fig. $10, C, D)$. The solid arrows in the host $(\mathrm{H})$ cortex (Fig. 10, $B$,
C) point to one of the multiple host NPY-NADPH-d doublelabeled neurons.

\section{Discussion}

Vasoactive intestinal polypeptide (VIP)-, somatostatin-14 (SS)-, and neuropeptide Y (NPY)-immunoreactive neuronal perikarya and fibers survived in every fetal cortical transplant. This and the peptide fibers traversing host-transplant interfaces represent new findings. Ebner et al. (1984) had previously transplanted fetal cortex into adult mouse neocortex and found immuno- 

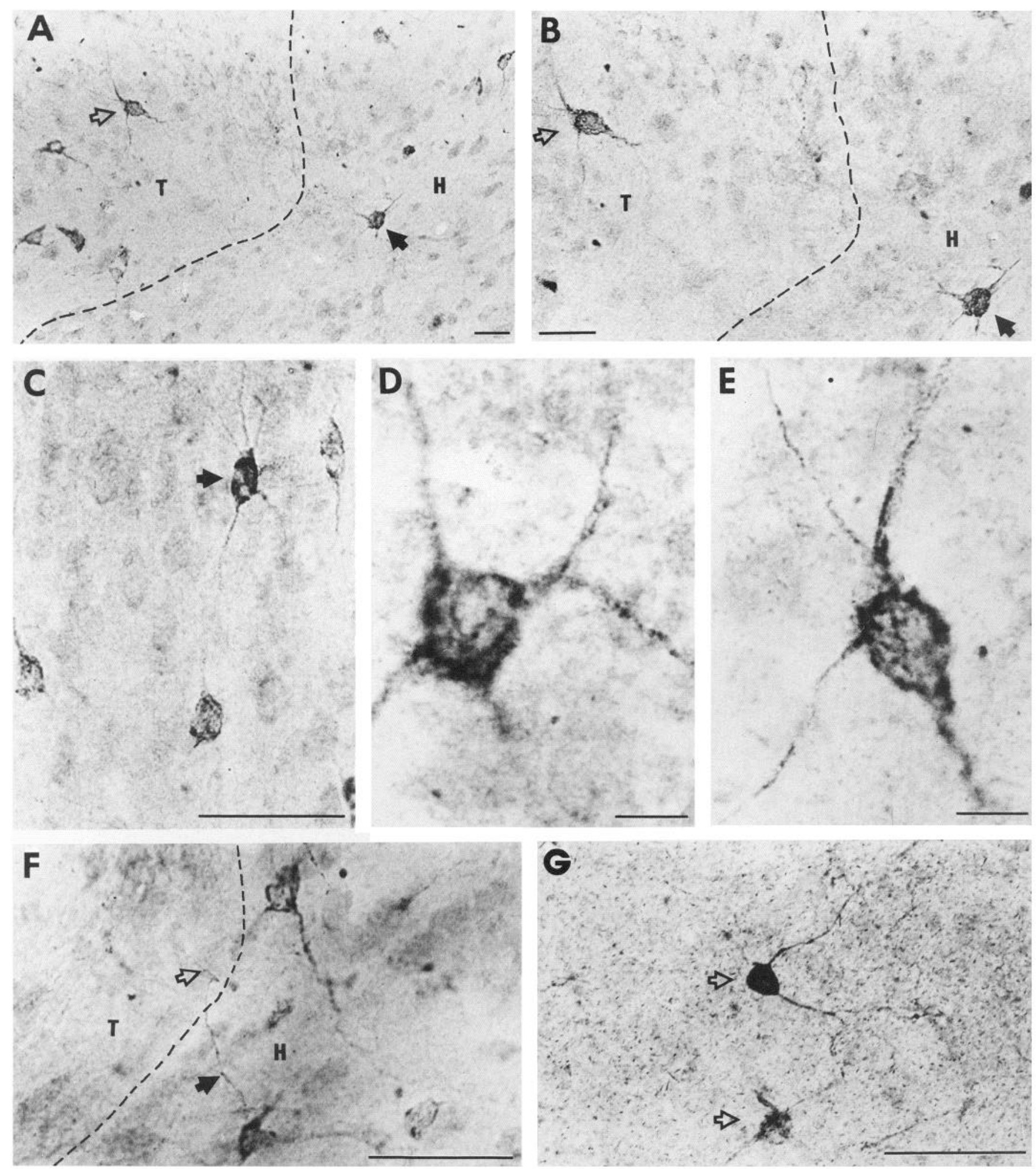

Figure 7. Photomicrographs of SS-like immunoreactive neurons in transplanted $(T)$ cortex $(A, B, E-G)$, and host $(H)$ cortex $(A-D, F)$. Note multipolar SS neurons in host (solid arrows, $A-D$ ) and transplant (open arrows, $A, B, E$ ). $F$, SS fiber runs from host (solid arrow) to transplant (open arrow). $G$, SS-positive, NADPH-d-positive neuron is located above an SS-positive, NADPH-d-negative neuron (both shown with open arrows) within a transplant. Criteria for drawing boundaries between host and transplant are given in Materials and Methods. Calibration bars, $40 \mu \mathrm{m}(A-$ $C, F, G) ; 10 \mu \mathrm{m}(D, E)$. 

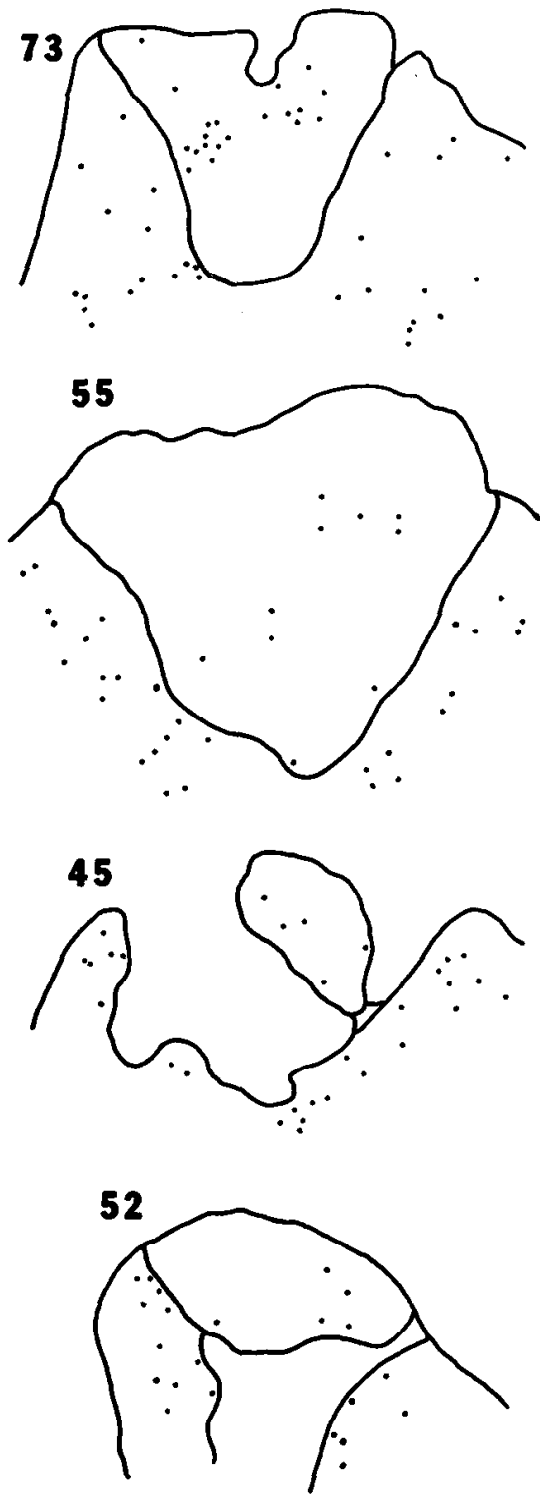
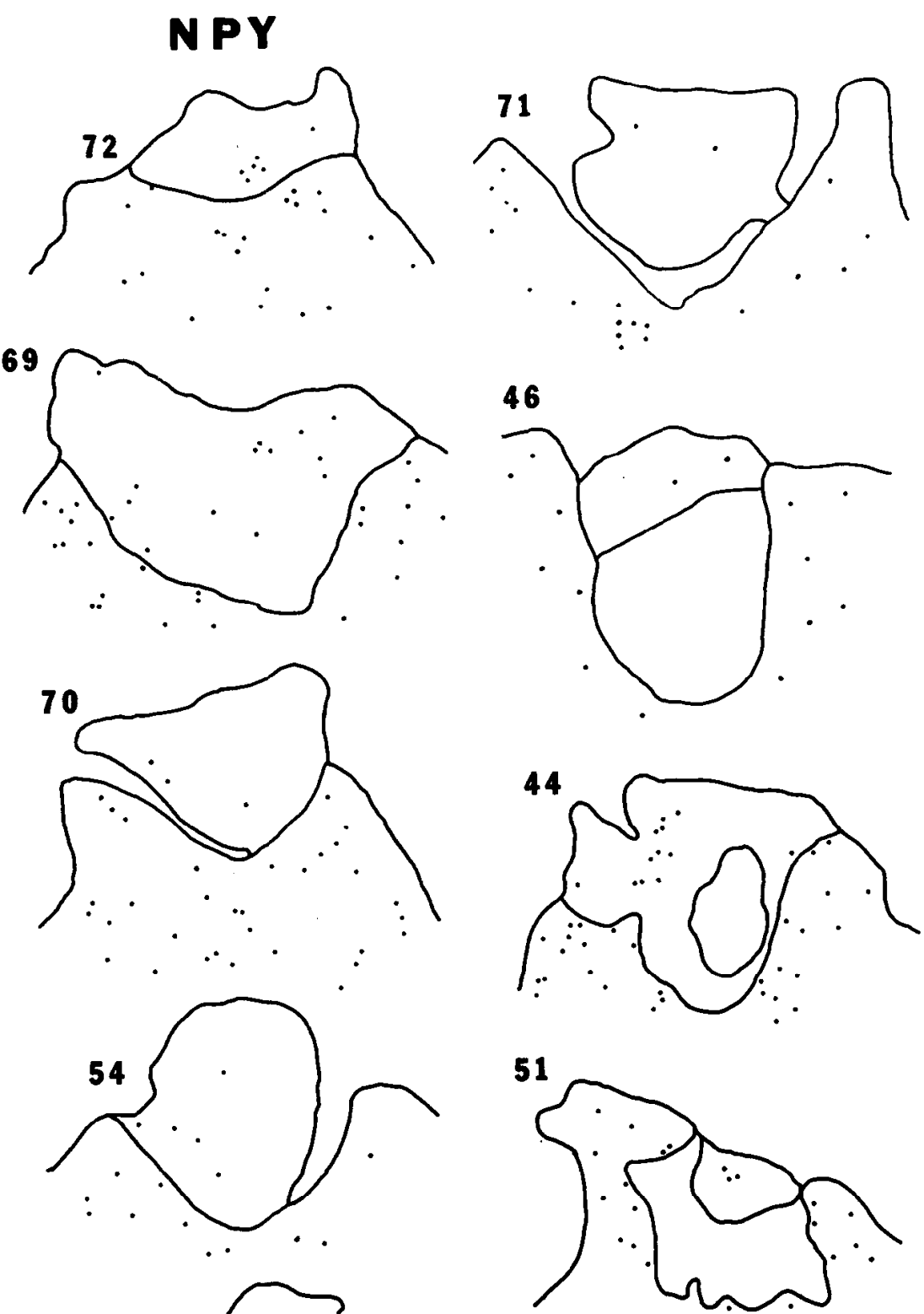

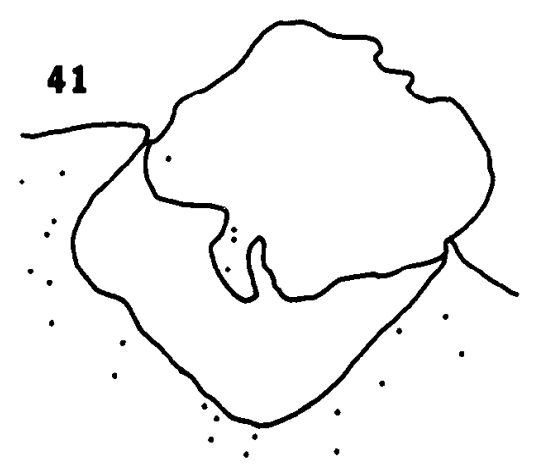

Figure 8. NPY-like immunoreactive neuronal perikarya for subjects $41-73$, plotted on camera lucida drawings of transplant and host cortex. Calibration bar, $1 \mathrm{~mm}$.

reactive peptide fibers in all transplants, but few or no immunoreactive perikarya in many. They concluded that technical problems limited visualization of immunoreactive perikarya. This is consistent with our results showing peptidergic perikarya and fibers in every fetal cortical transplant. Others have shown that peptidergic neurons survive in fetal hypothalamic grafts (Gash et al., 1980; Krieger et al., 1982) and in fetal cortex transplanted to spinal cord (Connor and Bernstein, 1986) or to neonatal rat cortex (Floeter and Jones, 1985).

Most peptide-containing cortical cells are nonpyramidal interneurons whose processes remain wholly within cortex and underlying white matter (Hendry et al., 1984; Jones and Hendry, 1986). This could contribute to the few transplant-host connections observed. Their scarcity could also be due to glial or 

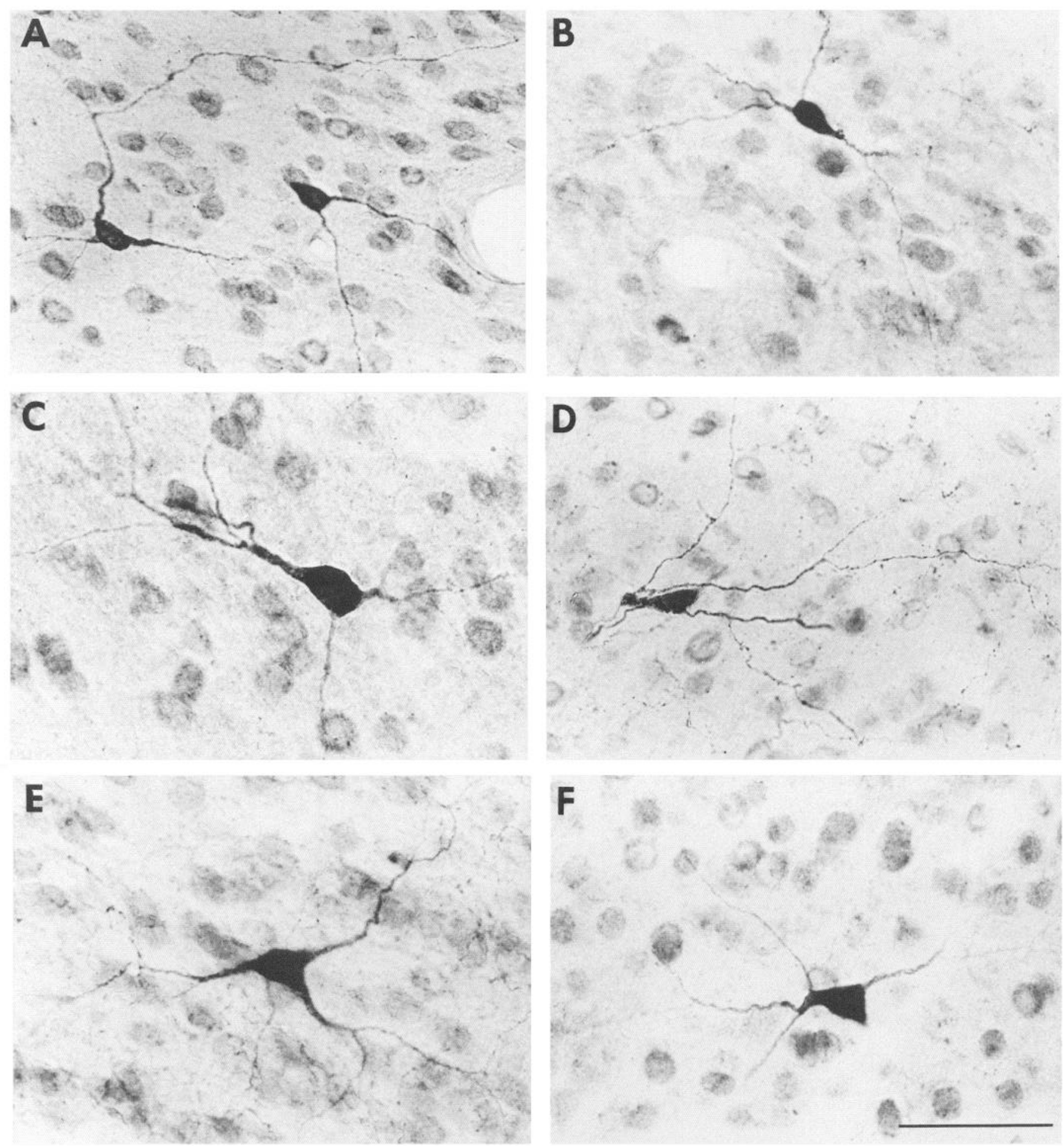

Figure 9. NPY neurons found within host brain $(A, C, E)$ and transplants $(B, D, F)$ on neutral red-counterstained sections. Note fiber near a vessel in host brain in $A$. Calibration bar, $40 \mu \mathrm{m}$.

other physical barriers, or to limited sprouting of peptidergic neurons in the transplant and host brain. This study documents for the first time, however, the crossing of peptidergic fibers at the host-transplant interface, and suggests that direct peptide interactions could occur between adult host cortex and fetal transplants.

The embryonic age at which VIP, SS, and NPY neurons undergo their last mitosis is not precisely known. The cells within embryonic day 18 (E18) fetal cortical transplants destined to be peptidergic might be pre- or postmitotic. It is known that NPY-immunoreactive fibers appear in embryonic cortex at E17 and perikarya at E19 (McDonald et al., 1982c; Allen et al., 1984; Woodhams et al., 1985). Some NADPH-d fibers and perikarya are present in E18 fetal rat cortex (Sharp et al., 1986). SS neurons 

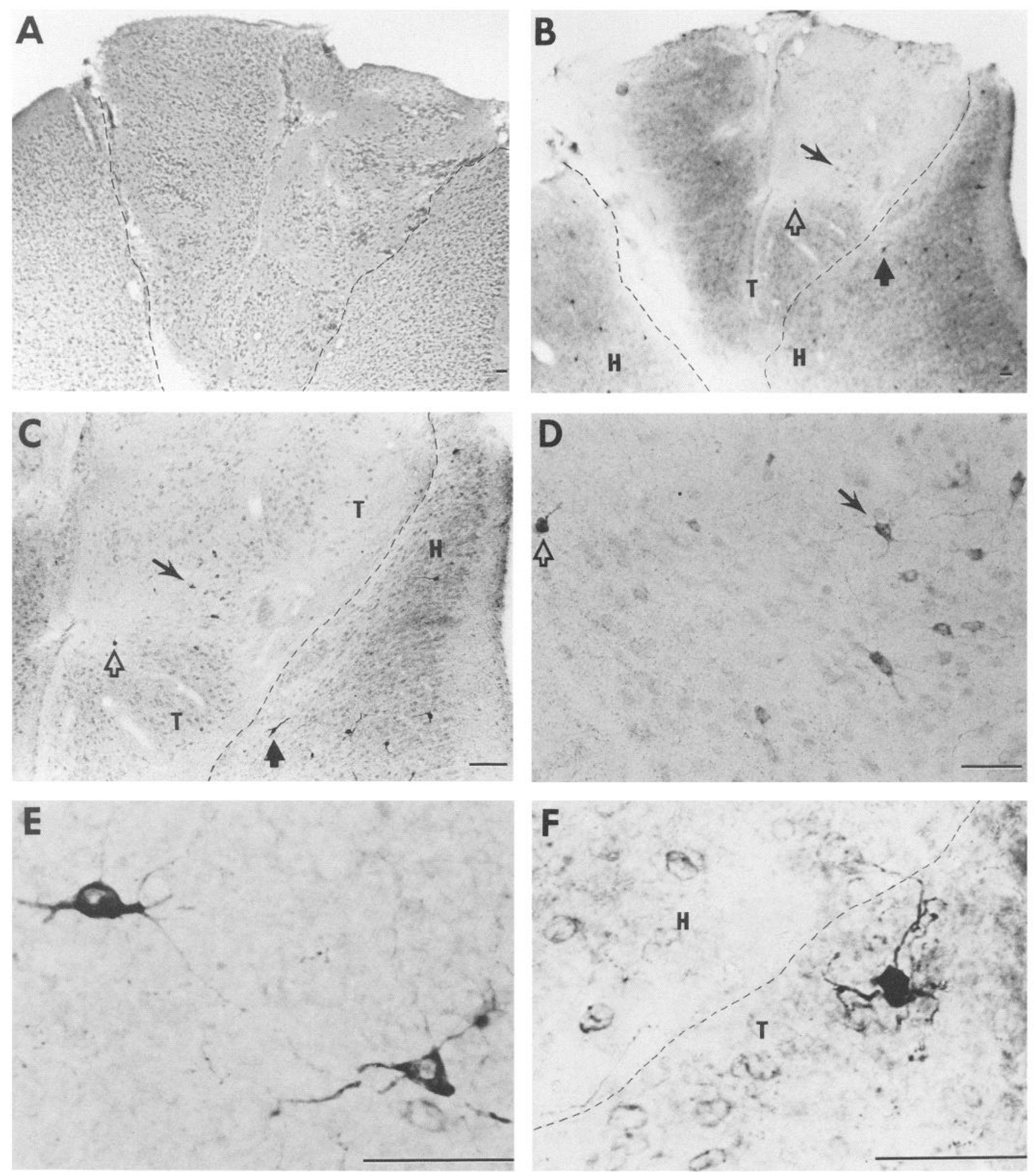

Figure 10. A, Neutral red-stained section of subject 73. B-E, NPY-immunostained, NADPH-d-stained sections from the same subject. A solid arrow in $B-D$ shows the same NPY-positive, NADPH-d-negative neuron within the transplant ( $T$ ), while an open arrow shows the same NPYpositive, NADPH-d-positive neuron. A solid arrow in $B$ and $C$ within the host $(H)$ cortex shows the same NPY-positive, NADPH-d-positive neuron. In $E$, two NPY-positive, NADPH-d-positive normal appearing neurons within a transplant are shown. In $F$, an abnormal NPY neuron within a transplant $(T)$ sends a process into the host $(H)$ cortex. Calibration bars, $40 \mu \mathrm{m}$. 
are detectable by E16 (McDonald et al., 1982b) and attain an adult pattern by 2 weeks after birth (Shiosaka et al., 1982). However, VIP-immunoreactive perikarya do not appear until 3-4 d after birth and are not mature until 4 weeks after birth (Emson et al., 1979; McDonald et al., 1982a). Therefore, some SS, NADPH-d, and NPY but not VIP would have been expressed in E18 fetal cortical tissue at the time of transplantation. If a cell must be postmitotic prior to expression of its adult peptides and enzymes, then some or all E18 SS, NADPH-d, and NPY cells are postmitotic. In addition, since VIP matures following transplantation, expression of a cell's peptide prior to or after transplantation does not appear to influence its survival.

VIP, SS, and NPY neurons develop adult morphology between 2 and 4 weeks after birth. The normal adult morphology of most transplanted peptidergic neurons indicates that these cells continued to develop normally after being transplanted at E18. Occasional morphological abnormalities of transplanted peptidergic neurons were observed, however. These abnormalities could have been caused by the trauma and anoxia of transplantation, by failure of other cells to survive or develop normally, or by alterations of trophic or growth factors.

Though most surviving VIP, SS, and NPY neurons appeared morphologically normal, they often did not migrate normally. Though VIP and SS neurons were found in all layers of normal adult neocortex, they were concentrated in layers 2,3 , and 6 (Larsson et al., 1976; Fuxe et al., 1977; Emson and Lindvall, 1979; Emson et al., 1979; Bennett-Clarke et al., 1980; Sims et al., 1980; Finley et al., 1981; Magistretti et al., 1981, 1984; McDonald et al., 1982a, b; Shiosaka et al., 1982; Sorensen, 1982; Chronwall et al., 1984; Johansson et al., 1984; Magistretti and Shorderet, 1984, 1985; Morrison et al., 1984; Hendry et al., 1985; Ramon y Cajal-Aguieras et al., 1985). The transplants of some subjects showed lamination of VIP and SS neurons, and one had a cell-free layer resembling the molecular layer.

Chang et al. (1986) reported near-normal lamination of fetal cortical transplants. Others have reported poor lamination (Hallas et al., 1980; Jaeger and Lund, 1981; Floeter and Jones, 1984; Sharp and Gonzalez, 1984; Castro et al., 1985). This variability of lamination reported in the literature is present within different transplants of this study and could be due to methodological variables. The proliferation of glial cells, which is important for normal lamination (Ichikawa et al., 1983), could be affected by transplantation. Any abnormality in the connections from host subcortical structures to fetal cortical transplants could also affect fetal cortex transplant lamination. Moreover, VIP exerts trophic effects on developing cortex (Brenneman et al., 1985; Brenneman and Eiden, 1986), and NPY and SS may affect normal brain development (Woodhams et al., 1985). Therefore, peptidergic neuron abnormalities might directly affect transplant lamination.

The decreased number of peptidergic neurons in some transplants could be due to several factors. The trauma and ischemia of transplantation, the failure to form appropriate connections, the loss of trophic interactions at a critical stage of development, and other factors could cause cell death. The neurons may survive but express no or undetectable levels of peptide, or express an abnormal peptide not detectable with the antibodies used. Glial cells might survive better than neurons or proliferate abnormally, resulting in a greater proportion of glia to neurons in some transplants. The survival of different types of peptidergic neurons appeared to be interrelated, since transplants containing many cells with a particular peptide had a greater number of cells with the other peptides. This could be due to an effect of one type of peptidergic neuron on the others, or to better overall survival of all cells.

The precise roles of VIP, SS, and NPY in normal brain are not known. VIP is found in all regions of mammalian cortex, primarily in bipolar neurons (Larsson et al., 1976; Fuxe et al., 1977; Emson and Lindvall, 1979; Emson et al., 1979; Sims et al., 1980; Magistretti et al., 1981, 1984; McDonald et al., 1982a; Morrison et al., 1984). The bipolar processes are parallel to one another and perpendicular to the pial surface. VIP neurons are among the few cortical peptidergic neurons that do not appear to colocalize with GABA (Jones and Hendry, 1986). These neurons, some of which do colocalize with acetylcholine in cortex (Eckenstein and Baughmann, 1984), may be excitatory, since VIP applied iontophoretically induced a long-lasting depolarization of identified rat corticospinal neurons (Phillis and Kirkpatrick, 1980). VIP is located within and released from cerebral cortex synaptosomes. Specific membrane receptors exist for VIP (De Souza et al., 1985), which may mediate the stimulatory effect of VIP on cAMP formation. VIP itself stimulates adenylate cyclase, and it also enhances the effects of noradrenaline and histamine on cAMP formation (Quik et al., 1978; van Calker et al., 1980; Magistretti et al., 1981, 1984; Rougon et al., 1983; Koh et al., 1984; Magistretti and Schorderet, 1984, 1985; Morrison et al., 1984). Moreover, VIP stimulates glycogenolysis in cortical slices via cAMP (Magistretti et al., 1981, 1984), probably by affecting glia that contain most of the brain glycogen. VIP could also mediate local metabolic activation via cAMP actions on enzymes, which would explain the increases in local glucose use produced by VIP injections into cortex (McCulloch and Edvinsson, 1980).

The reduced number of VIP neurons in most fetal cortical transplants could explain the decreased glucose metabolic rates of most fetal cortical transplants (Sharp and Gonzalez, 1984). VIP is found in peripheral ganglia that innervate extracranial vessel walls and is a potent extracranial vasodilating substance (McCulloch and Edvinsson, 1980; Edvinsson et al., 1984; Gibbins et al., 1984; Lee et al., 1984). It is not known whether local release of VIP by cortical neurons mediates both local vasodilatation of the vessels and increased glucose and oxygen consumption of the neurons.

According to Hendry et al. (1984), virtually all SS neurons in cortex colocalize with GABA. SS/GABA nonpyramidal, multipolar neurons are found in all cortical layers (Vincent et al., 1985). SS colocalizes with NPY but not with CCK and VIP in cortex (Vincent et al., 1982; Vincent and Johansson, 1983; Chronwall et al., 1984, 1985; Hendry et al., 1985; Jones and Hendry, 1986). In the best-stained brains there were many more SS than NPY neurons in the same regions of cortex, suggesting that only a fraction of SS neurons also contain NPY. This is in agreement with Hendry et al. (1984), who found that $24 \%$ of cortical neurons immunoreactive for either SS or NPY contained both peptides. This means there are SS/GABA/NPYpositive neurons, as well as many SS/CABA neurons, that do not contain NPY within normal cortex and cortical transplants. Our data suggest that SS/GABA/NPY cells are also NADPHd-positive and that SS/GABA-positive, NPY-negative cells are NADPH-d-negative. Monoamines modulate the SS-sensitive adenylate cyclase, and SS decreases the stimulatory effects of amines, corticotropin-releasing factor (CRF), and VIP on cAMP 
formation in primary neuronal and glial cultures (Chneiweiss et al., 1985).

Neuropeptide Y (NPY) cortical neurons are also nonpyramidal, intrinsic GABA-containing neurons. They are found in all cortical layers (McDonald et al., 1982c; Tatemoto et al., 1982; Vincent et al., 1982; Allen et al., 1983, 1984; Chronwall et al., 1984, 1985; Everitt et al., 1984; Hendry et al., 1984, 1985; Woodhams et al., 1985; Jones and Hendry, 1986). In this study, tissue stained for both NADPH-d and NPY revealed that cortical neurons that were NPY-positive but NADPH-d-negative were extremely rare. From this we concluded that virtually every NPY neuron colocalizes with NADPH-d in cortex. Moreover, it is likely that these same neurons colocalize with GABA, and that some also colocalize with SS (Viricent et al., 1982; Allen et al., 1983; Hendry et al., 1984, 1985).

It was therefore surprising to find a portion of one transplant with NPY-positive but NADPH-d-negative neurons-a situation that never occurred in normal cortex. These NPY neurons survived, but either failed to express the enzyme or expressed it in such low levels or in such an altered form that it could not be stained. This indicates that some populations of transplanted cells dissociated NADPH-d enzymatic activity from their peptide expression. This has implications for the expression of enzymes in cell lines in culture and following transplantation, and demonstrates that NPY cells can survive without expressing the NADPH-d enzyme, though some metabolic function may well be impaired. Though only recently identified, NPY has been shown to affect biological rhythms, to colocalize with peripheral and central adrenergic fibers and neurons, to affect consummatory behaviors, and to constrict cranial arteries and veins (Edvinsson et al., 1984; Everitt et al., 1984; Levine and Morley, 1984; Stanley and Leibowitz, 1984; Woodhams et al., 1985; Jones and Hendry, 1986).

As mentioned in Materials and Methods, the SS-14 antiserum used in the current experiments likely visualized SS-14 and SS28 neurons. The cross-reaction of the NPY antiserum with PYY and APP is not a problem in this study, since neither peptide is known to exist in mammalian cortex (Chronwall et al., 1985; Jones and Hendry, 1986). Other than VIP, peptides of the VIP family either are not found in cortex or occur in such low concentrations that they probably would not affect the interpretation of the VIP results of this study (Said and Mutt, 1970; Sims et al., 1980).

\section{References}

Allen, Y. S., T. E. Adrian, J. M. Allen, K. Tatemoto, T. J. Crow, S. R. Bloom, and J. M. Polak (1983) Neuropeptide Y distribution in the rat brain. Science 221:877-879.

Allen, J. M., G. P. McGregor, P. L. Woodhams, J. M. Polak, and S. R. Bloom (1984) Ontogeny of a novel peptide, neuropeptide Y (NPY) in rat brain. Brain Res. 303: 197-200.

Bennett-Clarke, C., M. A. Romagnano, and S. A. Joseph (1980) Distribution of somatostatin in the rat brain: Telencephalon and diencephalon. Brain Res. 188: 473-486.

Brenneman, D. E., and L. E. Eiden (1986) Vasoactive intestinal peptide and electrical activity influence neuronal survival. Proc. Natl. Acad. Sci. USA 83: 1159-1162.

Brenneman, D. E., L. E. Eiden, and R. E. Siegel (1985) Neurotrophic action of VIP on spinal cord cultures. Peptides (Suppl. 2) 6: 35-39.

Castro, A. J., J. Zimmer, N. A. Sunde, and E. L. Bold (1985) Transplantation of fetal cortex to the brain of newborn rats: A retrograde fluorescent analysis of callosal and thalamic projections from transplant to host. Neurosci. Lett. $60: 283-288$.

Chang, F.-L. F., J. G. Steedman, and R. D. Lund (1986) The lami- nation and connectivity of embryonic cerebral cortex transplanted into newborn rat cortex. J. Comp. Neurol. 244: 401-411.

Chneiweiss, H., J. Glowinski, and J. Prémont (1985) Modulation by monoamines of somatostatin-sensitive adenylate cyclase on neuronal and glial cells from the mouse brain in primary cultures. J. Neurochem. 44: 1825-1831.

Chronwall, B. M., T. N. Chase, and T. L. O'Donohue (1984) Coexistence of neuropeptide $Y$ and somatostatin in rat and human cortical and rat hypothalamic neurons. Neurosci. Lett. 52: 213-217.

Chronwall, B. M., D. A. DiMaggio, V. J. Massari, V. M. Pickel, D. A Ruggiero, and T. L. O'Donohue (1985) The anatomy of neuropeptide- $Y$-containing neurons in rat brain. Neuroscience 15: 1159-1181.

Connor, J. R., and J. J. Bernstein (1986) Vasoactive intestinal polypeptide neurons in fetal cortical homografts to adult rat spinal cord. Brain Res. 367: 214-221.

De Souza, E. B., H. Seifert, and M. J. Kuhar (1985) Vasoactive intestinal peptide receptor localization in rat forebrain by autoradiography. Neurosci. Lett. 56: 113-120.

Duhamel, R. C., and D. A. Johnson (1985) Use of nonfat dry milk to block nonspecific nuclear and membrane staining by avidin conjugates. J. Histochem. Cytochem. 33: 711-714.

Ebner, F. F., J. A. Olschowka, and D. M. Jacobowitz (1984) The development of peptide-containing neurons within neocortical transplants in adult mice. Peptides 5: 103-113.

Eckenstein, F., and R. W. Baughmann (1984) Two types of cholingeric innervation in cortex, one co-localized with vasoactive intestinal polypeptide. Nature 309: 153-155.

Edvinsson, L., P. Emson, J. McCulloch, K. Tatemoto, and R. Uddman (1984) Neuropeptide Y: Immunocytochemical localization to and effect upon feline pial arteries and veins in vitro and in situ. Acta Physiol. Scand. 122: 155-163.

Emson, P. C., and O. Lindvall (1979) Distribution of putative neurotransmitters in the neocortex. Neuroscience 4:1-30.

Emson, P. C., R. C. T. Gilbert, I. Loren, J. Fahrenkrug, F. Sundler, and O. B. Schaffalitzky de Muckadell (1979) Development of vasoactive intestinal polypeptide (VIP) containing neurons in the rat brain. Brain Res. 177: 437-444.

Everitt, B. J., T. Hökfelt, L. Terenius, K. Tatemoto, V. Mutt, and M. Goldstein (1984) Differential co-existence of neuropeptide Y (NPY)like immunoreactivity with catecholamines in the central nervous system of the rat. Neuroscience 11: 443-462.

Finley, J. C. W., J. L. Maderdrut, L. J. Roger, and P. Petrusz (1981) The immunocytochemical localization of somatostatin-containing neurons in the rat central nervous system. Neuroscience 6: 21732192.

Floeter, M. K., and E. G. Jones (1984) Connections made by transplants to the cerebral cortex of rat brains damaged in utero. J. Neurosci. 4: 141-150.

Floeter, M. K., and E. G. Jones (1985) Transplantation of fetal postmitotic neurons to rat cortex: Survival, early pathway choices and long-term projections of outgrowing axons. Dev. Brain Res. 22: 1938.

Fuxe, K., T. Hökfelt, S. I. Said, and V. Mutt (1977) Vasoactive intestinal polypeptide and the nervous system: Immunohistochemical evidence for localization in central and peripheral neurons, particularly intracortical neurons of the cerebral cortex. Neurosci. Lett. 5: 241-246.

Gash, D., J. R. Sladek, and C. D. Sladek (1980) Functional development of grafted vasopressin neurons. Science 210: 1367-1369.

Gibbins, I. L., J. E. Brayden, and J. A. Bevan (1984) Perivascular nerves with immunoreactivity to vasoactive intestinal polypeptide in cephalic arteries of the cat: Distribution, possible origins and functional implications. Neuroscience 13: 1327-1346.

Gonzalez, M. F., and F. R. Sharp (1987) Fetal frontal cortex transplanted to injured motor/sensory cortex of adult rats. I. NADPHdiaphorase neurons. J. Neurosci. 7: 2991-3001.

Hallas, B. H., G. D. Das, and K. G. Das (1980) Transplantation of brain tissue in the brain of rat. II. Growth characteristics of neocortical transplants in hosts of different ages. Am. J. Anat. 158: 147-159.

Hendry, S. H. C., E. G. Jones, J. DeFelipe, D. Schmechel, C. Brandon, and P. C. Emson (1984) Neuropeptide-containing neurons of the cerebral cortex are also GABA-ergic. Proc. Natl. Acad. Sci. USA 81: 6526-6530.

Hendry, S. H. C., E. G. Jones, and P. C. Emson (1984) Morphology, distribution, and synaptic relations of somatostatin-and neuropeptide 
$\mathrm{Y}$-immunoreactive neurons in rat and monkey neocortex. J. Neurosci. 4: 2497-2517.

Hsu, S.-M., L. Raine, and H. Fanger (1981) The use of avidin-biotinperoxidase complex $(\mathrm{ABC})$ in immunoperoxidase techniques: A comparison between $\mathrm{ABC}$ and unlabeled antibody $(\mathrm{P} \Lambda \mathrm{P})$ procedures. $\mathrm{J}$. Histochem. Cytochem. 29: 577-580.

Ichikawa, M., S. Takashi, and Y. Hirata (1983) Spatial and temporal pattern of postnatal proliferation of glial cells in the parietal cortex of the rat. Dev. Brain Res. 9: 181-187.

Jaeger, C. B., and R. D. Lund (1981) Transplantation of embryonic occipital cortex to the brain of newborn rats: A Golgi study of mature and developing transplants. J. Comp. Neurol. 200: 213-230.

Johansson, O., T. Hökfelt, and R. P. Elde (1984) Immunohistochemical distribution of somatostatin-like immunoreactivity in the central nervous system of the adult rat. Neuroscience 13: 265-339.

Jones, E. G., and S. H. C. Hendry (1986) Co-localization of GABA and neuropeptides in neocortical neurons. Trends Neurosci. 9: 7176.

Koh, S.-W. M., A. Kyritsis, and G. J. Chader (1984) Interaction of neuropeptides and cultured glia (Müller) cells of the chick retina: Elevation of intracellular cyclic AMP by vasoactive intestinal peptide and glucagon. J. Neurochem. 43: 199-203.

Krieger, D. T., M. J. Perlow, M. J. Gibson, T. F. Davis, E. A. Zimmerman, M. Ferin, and H. M. Charlton (1982) Brain grafts reverse hypogonadism of gonadotropin releasing hormone deficiency. Nature 298: 468-471.

Larsson, L.-I., J. Fahrenkrug, O. Schaffalitzky de Muckadell, F. Sundler, and R. Håkanson (1976) Localization of VIP to central and peripheral neurons. Proc. Natl. Acad. Sci. USA 73: 3197-3200.

Lee, T. J.-F., A. Saito, and I. Berezin (1984) Vasoactive intestinal polypeptide-like substance: The potential transmitter for cerebral vasodilation. Science 224: 898-901.

Levine, A. S., and J. E. Morley (1984) Neuropeptide Y: A potent inducer of consummatory behavior in rats. Peptides 5: 1025-1029.

Magistretti, P. J., and M. Schorderet (1984) VIP and noradrenaline act synergistically to increase cyclic AMP in cerebral corlex. Nature 308: 280-282.

Magistretti, P. J., and M. Schorderet (1985) Norepinephrine and histamine potentiate the increases in cyclic adenosine $3^{\prime}: 5^{\prime}$-monophosphate elicited by vasoactive intestinal polypeptide in mouse cerebral cortical slices: Mediation by alpha-adrenergic and $\mathrm{H} 1$-histaminergic receptors. J. Neurosci. 5: 362-368.

Magistretti, P. J., J. H. Morrison, W. J. Shoemaker, V. Sapin, and F. E. Bloom (1981) Vasoactive intestinal polypeptide induces glycogenolysis in mouse cortical slices: A possible regulatory mechanism for local control of energy metabolism. Proc. Natl. Acad. Sci. USA 78: 6535-6539.

Magistretti, P. J., J. H. Morrison, W. J. Shoemaker, and F. E. Bloom (1984) Morphological and functional correlates of VIP neurons in cerebral cortex. Peptides 5: 213-218.

McCulloch, J., and L. Edvinsson (1980) Cerebral circulatory and metabolic effects of vasoactive intestinal polypeptide. Am. J. Physiol. 238: $\mathrm{H} 449-\mathrm{H} 456$.

McDonald, J. K., J. C. Parnavelas, A. N. Karamanlidis, and N. Brecha (1982a) The morphology and distribution of peptide-containing neurons in the adult and developing visual cortex of the rat. II. Vasoactive intestinal polypeptide. J. Neurocytol. 11: 825-837.

McDonald, J. K., J. C. Parnavelas, A. N. Karamanlidis, N. Brecha, and J. I. Koenig (1982b) The morphology and distribution of pepiidecontaining neurons in the adult and developing visual cortex of the rat. I. Somatostatin. J. Neurocytol. 11: 809-824.

McDonald, J. K., J. C. Parnavelas, A. N. Karamanlidis, and N. Brecha (1982c) The morphology and distribution of peptide-containing neurons in the adult and developing visual cortex of the rat. IV. Avian pancreatic polypeptide. J. Neurocytol. 11: 985-995.

Morrison, J. H., P. J. Magistretti, R. Benoit, and F. E. Bloom (1984) The distribution and morphological characteristics of the intracortical VIP-positive cell: An immunohistochemical analysis. Brain Res. 292. 269-282.
Philis, J. W., and J. R. Kirkpatrick (1980) The actions of motilin, luteinizing hormone releasing hormone, cholecystokinin, somatostatin, vasoactive intestinal peptide and other peptides on rat cerebral cortical neurons. Can. J. Physiol. Pharmacol. 58: 612-623.

Quik, M., L. L. Iversen, and S. R. Bloom (1978) Effect of vasoactive intestinal peptide (VIP) and other peptides on cAMP accumulation in rat brain. Biochem. Pharmacol. 27: 2209-2213.

Ramón y Cajal-Agüeras, S., P. Contamina, P. Parra, L. Martinez-Millán, J. A. DeCarlos, and C. Ramo (1985) The distribution of somatostatin-immunoreactive neurons in the visual cortex of adult rabbits and during postnatal development. Brain Res. 359: 379-382.

Rougon, G., M. Noble, and A. W. Mudge (1983) Neuropeptides modulate the beta adrenergic response of purified astrocytes in vitro. $\mathrm{Na}$ ture 305: 715-717

Sagar, S. M., P. E. Marshall, and D. M. D. Landis (1985) Immunoreactive somatostatin in the rat retina: Light microscopic immunocytochemistry and chromatographic characterization. Brain Res. 336 . 235-242.

Said, S. I., and V. Mutt (1970) Polypeptide with broad biological activity: Isolation from small intestine. Science 169: 1217-1218.

Sharp, F. R., and M. F. Gonzalez (1984) Fetal frontal cortex transplant $\left({ }^{14} \mathrm{C}\right)$ 2-deoxyglucose uptake and histology: Survival in cavities of host rat brain motor cortex. Neurology 34: 1305-1311.

Sharp, F. R., M. F. Gonzalez, D. M. Ferriero, and S. M. Sagar (1986) Injured adult neocortical neurons sprout fibers into surviving fetal frontal cortex transplants: Evidence using NADPH-diaphorase staining. Neurosci. Lett. 65: 204-208.

Sherer-Singler, U., S. R. Vincent, H. Kimura, and E. G. McGeer (1983) Demonstration of a unique population of neurons with NADPHdiaphorase histochemistry. J. Neurosci. Methods 9: 229-234.

Shiosaka, S., K. Takatsuki, M. Sakanaka, S. Inagaki, H. Takagi, E. Senba, Y. Kawai, H. Iida, H. Minagawa, Y. Hara, T. Matsuzaki, and M. Tohyama (1982) Ontogeny of somatostatin-containing neuron system of the rat: Immunohistochemical analysis. II. Forebrain and diencephalon. J. Comp. Neurol. 204: 211-224.

Sims, K. B., D. L. Hoffman, S. I. Said, and E. A. Zimmerman (1980) Vasoactive intestinal polypeptide (VIP) in mouse and rat brain: An immunocytochemical study. Brain Res. 186: 165-183.

Sorensen, K. V. (1982) Somatostatin: Localization and distribution in the cortex and the subcortical white matter of human brain. Neuroscience $7:$ : $227-1232$.

Stanley, B. G., and S. F. Leibowitz (1984) Neuropeptide Y: Stimulation of feeding and drinking by injection into the paraventricular nucleus. Life Sci. 35: 2635-2642.

Tatemoto, K., M. Carlquist, and V. Mutt (1982) Neuropeptide Y: A novel brain peptide with structural similarities to peptide $Y Y$ and pancreatic polypeptide. Nature 296: 659-660.

van Calker, D., M. Müller, and B. Hamprecht (1980) Regulation by secretin, vasoactive intestinal peptide, and somatostatin of cyclic AMP accumulation in cultured brain cells. Proc. Natl. Acad. Sci. USA 77: 6907-6911.

Vincent, S. R., and O. Johansson (1983) Striatal neurons containing both somatostatin- and avian pancreatic polypeptide (APP)-like immunoreactivities and NADPH-diaphorase activity: A light and electron microscopic study. J. Comp. Neurol. 217: 264-270.

Vincent, S. R., L. Skirboll, T. Hökfelt, O. Johansson, J. M. Lundberg, R. P. Elde, L. Terenius, and J. Kimmel (1982) Coexistence of somatostatin- and avian pancreatic polypeptide (APP)-like immunoreactivity in some forebrain neurons. Neuroscience 7: 439-446.

Vincent, S. R., C. H. S. McIntosh, A. M. J. Buchan, and J. C. Brown (1985) Central somatostatin systems revealed with monoclonal antibodies. J. Comp. Neurol. 238: 169-186.

Woodhams, P. L., Y. S. Allen, J. McGovern, J. M. Allen, S. R. Bloom, R. Balazs, and J. M. Polak (1985) Immunohistochemical analysis of the early ontogeny of the neuropeptide $\mathrm{Y}$ system in rat brain. Neuroscience 15: 173-202. 